\title{
PARTISIPASI PETERNAK DALAM PELAKSANAAN PROGRAM INSEMINASI BUATAN DI KABUPATEN LOMBOK BARAT NUSA TENGGARA BARAT
}

\author{
M. Yasin'
}

\section{INTISARI}

Penelitian ini bertujuan untuk : (a) mempelajari karakteristik individu dan tingkat partisipasi peternak, (b) membandingkan tingkat partisipasi peternak di daerah dominan lahan persawahan dengan daerah dominan lahan kering, dan (c) mengetahui hubungan antara karakteristik individu dan tingkat partisipasi peternak dalam pelaksanaan program inseminasi buatan (IB) di Kabupaten Lombok Barat Propinsi Nusa Tenggara Barat. Penentuan sampel menggunakan metode cluster bertahap, yakni sebagai berikut: (1) Dari sembilan unit lokasi IB (ulib) di Kabupaten Lombok Barat, ditetapkan empat ulib sampel, yakni : (a) Kecamatan Narmada dan Kecamatan Gerung (ulib daerah dominan lahan persawahan), dan (b) Kecamatan Tanjung dan Kecamatan Gangga (ulib daerah dominan lahan kering); (2) dari tiap-tiap ulib sampel dipilih dua desa sampel secara purposive, yaitu (a) Desa Kebun Ayu, Jembatan Kembar, Selat dan Sedau untuk daerah dominan lahan persawahan dan (b) Desa Tanjung, Sokong, Gondang dan Rempek untuk daerah dominan lahan kering. (3) selanjutnya, dari tiap-tiap strata daerah sampel dipilih 50 orang peternak sampel secara systematic sampling. Pengumpulan data primer dilakukan melalui wawancara langsung kepada responden dengan berpedoman pada instrumen yang telah diuji tingkat validitas dan reliabilitasnya. Untuk mengetahui karakteristik individu dan tingkat partisipasi peternak dilakukan analisis distribusi frekuensi dan tabulasi silang, kemudian dilanjutkan dengan pemberian skor. Untuk melihat perbedaan tingkat partisipasi peternak di daerah dominan lahan persawahan dan peternak di daerah dominan lahan kering dilakukan uji U Mann-Whitney, sedangkan untuk menganalisis hubungan antara karakteristik individu dan tingkat partisipasi peternak digunakan uji statistik korelasi Rank Spearman. Hasil analisis menunjukkan bahwa karakteristik individu peternak yang dominan adalah: (a) seluruh peternak masih berusia produktif, (b) sebagian besar tidak tamat Sekolah Dasar, (c) jumlah tanggungan keluarga sebagian besar antara empat sampai lima orang, (d) pengalaman sebagai akseptor IB rata-rata dua tahun, dan (e) tingkat pengetahuan tentang IB sebagian besar tergolong rendah. Secara keseluruhan, tingkat partisipasi peternak rata-rata tergolong sedang. Tingkat partisipasi peternak di daerah dominan lahan persawahan lebih tinggi daripada partisipasi peternak di daerah dominan lahan kering. Aspek partisipasi yang berbeda sangat nyata adalah aktivitas dalam memasyarakatkan IB $(Z=3097 ; \mathrm{P}<0,01)$, sedangkan aspek yang berbeda nyata adalah partisipasi dalam memberikan usul/pendapat tentang IB $(\mathrm{Z}=2767 ; \mathrm{P}<0,05)$. Karakteristik individu yang menunjukkan adanya korelasi yang bermakna dengan tingkat partisipasi peternak ialah umur, pendidikan dan pengetahuan tentang IB.

(Kata kunci : Partisipasi, Karateristik individu, Inseminasi buatan).

Buletin Peternakan 29 (3) : 139 - 149, 2005

${ }^{1}$ Fakultas Petemakan Universitas Mataram. 


\title{
FARMER PARTICIPATION IN EXECUTING ARTIFICIAL INSEMINATION PROGRAM IN WEST LOMBOK REGENCY WEST NUSA TENGGARA PROVINCE
}

\begin{abstract}
This research was aimed: (a) to observe individual characteristic and the level of farmer participation, (b) to compare the participation level between farmer living in rice field dominant area and dry land dominant area, and (c) to determine the relationship between individual characteristic and farmer participation level in executing artificial insemination program (AI). Determination of research sample used phases cluster method, with the following steps : (1) from nine location unit (ulib) in West Lombok Regency, there was four ulib beingchosen as the sampling sources : (a) Ulib of Narmada Subdistrict and ulib of Gerung Subdistrict (representing rice field dominant area), and (b) Ulib of Tanjung Subdistrict and ulib of Gangga Subdistrict (representing dry land dominant area). (2) Two villages sample were chosen from each ulib purposively, that were (a) Village of Kebun Ayu, Jembatan Kembar, Selat, and Sedau representing rice field dominant area and (b) Village of Tanjung, Sokong, Gondang and Rempek representing dry land dominant area. (3) from each sample village 50 farmer were chosen by systematic sampling. Primary data collection was conducted through direct interview to respondent based on the instrument, that have been tested its validity and reliability. To know the individual characteristic and the level of farmer participation, the analysis of frequency distribution and cross tabulation were conducted, and then continued with scoring. To see the difference of participation level between farmers who lived in rice field dominant area and in dry land dominant area, U Mann-Whitney Test was conducted. Analysis on the relationship between individual characteristic and the participation level of farmers, used Rank Spearman Statistical Correlation Test. The results indicated that the most dominant individual characteristic of farmers were : (a) All farmers were still in productive age, (b) Most of them were not finished the Elementary School yet, (c) Amount of family responsibility was between $4-5$ people, (d) The average length of experience as acceptor of AI was two years, and (e) Most of farmers had little knowledge about AI. Generally, the level of farmer participation was in medium scale. The level of farmer participation who lived in rice field dominant area was higher than that in dry land dominant area. One of participation aspect that has significant difference was activity in socializing $\mathrm{AI}(\mathrm{Z}=3097 ; \mathrm{P}<0,01)$, while the aspect that had significant difference was participation in giving suggestion/opinion about $\mathrm{AI}(\mathrm{Z}=$ 2767; $\mathrm{P}<0,05$ ). Individual characteristic which showed significant correlation with the level of farmers participation were : age, level of education and level of knowledge about AI.
\end{abstract}

(Key words : Participation, Individual characteristic, Artificial insemination).

\section{Pendahuluan}

Dalam upaya pengembangan usahatani ternak sapi di Kabupaten Lombok Barat Propinsi Nusa Tenggara Barat (NTB), bahkan seluruh Indonesia, permasalahan utama yang dihadapi adalah rendahnya peningkatan populasi setiap tahunnya. Masalah berikutnya adalah rendahnya produktivitas ternak sapi, baik sebagai ternak potong maupun sebagai ternak kerja. Secara umum penyebabnya adalah minimnya modal serta rendahnya penguasaan teknologi peternakan oleh para peternak. Untuk mengatasi permasalahan tersebut, maka salah satu upaya yang dilakukan oleh pemerintah daerah setempat adalah mengintensifkan pelaksanaan program inseminasi buatan (IB) yang sudah diperkenalkan kepada masyarakat tani sejak tahun 1976.

Pada tahun pertama penerapan IB di Lombok Barat, hasilnya memang kurang memuaskan, namun berkat upaya yang lebih intensif dengan melibatkan lebih banyak ternak sapi milik rakyat, ternyata hasilnya cukup 
menggembirakan. Hal ini terbukti dari jumlah kelahiran pedet hasil IB yang cukup tinggi.

Permasalahan yang timbul adalah meskipun penerapan IB telah memperlihatkan hasil yang positif, namun tidak dapat dipastikan bahwa para peternak akan secara konsisten menerapkan teknologi IB pada sapi-sapi mereka, Bahkan bagi peternak yang telah menerapkan teknologi IB secara kontinyu pun, belum dapat dipastikan bahwa di masa mendatang akan selalu berpartisipasi dalam menerapkan teknologi tersebut.

Makna partisipasi itu sendiri bagi seseorang maupun kelompok sosial amatlah penting. Menurut Hunneryager dan Heckman (1992), salah satu hasil partisipasi yang penting adalah bantuannya agar individu maupun masyarakat menjadi lebih matang/dewasa dan bertanggung jawab. Hal yang hampir sama juga dikemukakan oleh Ndraha (1990), bahwa antara partisipasi dan kemauan masyarakat desa untuk berkembang secara mandiri terdapat kaitan yang erat sekali. Kesediaan masyarakat untuk berpartisipasi merupakan tanda adanya kemampuan masyarakat tersebut untuk berkembang secara mandiri.

Kecenderungan perotangan untuk berpartisipasi dalam urusan kemasyarakatan bergantung pada beragam faktor. Tentang hal ini, berdasarkan hasil penelitian Angel yang disitasi oleh Soetarso (1979) menunjukkan bahwa faktor umur, pendapatan, pekerjaan, pendidikan, dan lama menetap di suatu daerah ternyata berhubungan dengan kecendrungan masyarakat untuk berpartisipasi.

Kabupaten Lombok Barat, berdasarkan kondisi lahan pertaniannya, dapat dibedakan antara daerah yang didominasi oleh lahan kering (berupa tegalan dan sawah tadah hujan) dan daerah yang didominasi oleh lahan persawahan dengan sistem irigasi. Lombok Barat bagian utara dan selatan didominasi oleh lahan kering, sedangkan bagian tengah merupakan daerah dominan lahan persawahan. Mengingat program IB telah menyebar ke seluruh wilayah Lombok Barat, diperkirakan perbedaan kondisi daerah asal peternak akan mempengaruhi tingkat partisipasinya dalam pelaksanaan program tersebut.
Ruang lingkup partisipasi tidak hanya terbatas pada keikutsertaan atau keterlibatan masyarakat atau seseorang secara fisik saja, tetapi juga keterlibatan secara mentalitas dan emosional dalam suatu program atau kegiatan pembangunan.

Berdasarkan pokok-pokok pemikiran di atas, maka dilakukan penelitian yang bertujuan untuk : 1) mempelajari karakteristik individu dan tingkat partisipasi peternak; 2) membandingkan tingkat partisipasi peternak yang berdomisili di daerah dominan lahan kering dan dominan lahan persawahan; dan 3) mengetahui hubungan antara karakteristik individu dengan tingkat partisipasi peternak dalam pelaksanaan program IB.

Hasil penelitian ini diharapkan akan dapat berguna sebagai bahan pertimbangan bagi para penentu kebijaksanaan dalam perencanaan program pengembangan IB, serta sebagai bahan acuan dalam penyusunan program penyuluhan peternakan, khususnya tentang IB pada ternak sapi.

\section{Materi dan Metode}

Penelitian ini didesain sebagai penelitian survei yang bersifat deskriptif-korelasional. Penelitian dilaksanakan di Kabupaten Lombok Barat Propinsi NTB yang meliputi sembilan unit lokasi IB (ulib) yang berada di tingkat kecamatan. Berdasarkan kondisi wilayahnya, ulib tersebut dapat dikelompokkan menjadi dua kategori, yaitu ulib pada daerah dominan lahan kering dan ulib pada daerah dominan lahan persawahan.

Sebagai populasi penelitian adalah semua peternak sapi yang tercatat sebagai peserta (akseptor) IB dan bertempat tinggal di desa-desa (sub unit lokasi IB) yang merupakan unit lokasi terkecil daerah penelitian.

Penentuan sampel dilakukan secara cluster bertahap. Metode ini digunakan mengingat luasnya daerah operasional program IB dan besarnya populasi peternak yang tercatat sebagai akseptor. Adapun urutan langkah dalam penentuan sampel penelitian adalah sebagai berikut:

1. Dari semua ulib di Kabupaten Lombok Barat, ditetapkan empat ulib sampel yang 
terdiri dari dua ulib daerah dominan lahan kering dan dua ulib daerah dominan lahan persawahan. Penetapan keempat ulib sampel tersebut dilakukan secara purposive dengan memperhatikan lamanya program IB beroperasi dan jumlah akseptor yang dilayani. Dalam penelitian ini, ulib yang diambil sebagai sampel yakni ulib yang telah beroperasi sekurang-kurangnya lima tahun, dan pada ulib tersebut terdapat akseptor IB yang lebih banyak dibandingkan dengan ulib lainnya. Berdasarkan ketentuan tersebut, maka terpilihlah : (1) Ulib Kecamatan Tanjung dan Gangga (daerah dominan lahan kering), dan (2) Ulib Kecamatan Narmada dan Gerung (daerah dominan lahan persawahan).

2. Dengan pertimbangan yang sama, maka dari tiap-tiap ulib sampel dipilih dua desa sampel juga secara purposive, yaitu : (1) Desa Tanjung, Sokong, Gondang, dan Rempek untuk daerah dominan lahan kering, dan (2) Desa Kebun Ayu, Jembatan Kembar, Selat, dan Sedau untuk daerah dominan lahan persawahan.

3. Selanjutnya, dari tiap-tiap bagian daerah sampel, dipilih 50 orang peternak sampel secara systematic sampling. Metode ini digunakan mengingat populasi akseptor IB yang cukup banyak, namun semuanya tercatat dengan baik. Selain itu, seluruh akseptor relatif homogen terutama ditinjau dari segi pengalaman dan keterampilannya.

Pengumpulan data primer dilakukan melalui wawancara langsung kepada responden dengan berpedoman pada kuesioner yang telah dipersiapkan dan telah diuji tingkat validitas serta reliabilitasnya, Metode pengujian validitas yang digunakan adalah menyesuaikan isi koesioner dengan kajian-kajian pustaka yang berkaitan dengan konsep teoritis mengenai karakteristik individu dan tingkat partisipasi peternak dalam penerapan IB. Sebagai pembanding, digunakan pula hasil-hasil penelitian yang relevan, yang pernah dilakukan peneliti sebelumnya.

Reliabilitas adalah indeks yang menunjukkan tingkat kepercayaan atau keterandalan terhadap suatu alat pengukur (instrumen penelitian). Jika suatu alat pengukur dipakai dua kali (untuk mengukur gejala yang sama) dan hasilnya relatif konsisten, maka alat pengukur tersebut dikatakan realibel (Ancok 1991). Untuk mencapai hal tersebut, dilakukan uji reliabilitas instrumen dengan teknik belah dua, dengan menggunakan rumus berikut:

Keterangan:

r.tot : angka reliabilitas keseluruhan item

r.tt : angka korelasi belahan pertama dan belahan kedua

Hasil pengujian menunjukkan r.tot $=0,91$. Menurut Iskandar dan Nitimihardjo (1992), koefisien reliabilitas instrumen untuk mengukur tingkat partisipasi sosial berkisar antara 0,89 0,95 .

Variabel yang diamati dan diukur meliputi karakteristik peternak sebagai variable bebas (Independent Variable) dan tingkat partisipasi peternak dalam program pengembangan IB sebagai variable terikat (Dependent Variable).

Untuk mengetahui karekateristik dan tingkat partisipasi peternak dilakukan analisis distribusi frekuensi dan tabulasi silang (Wignjosoebroto, 1989). Pengukuran terhadap kedua jenis variabel tersebut dilakukan dengan sistem skor dengan pendekatan skala berjenjang, dan semua pengukuran menggunakan tiga kategori. Untuk menganalisis hubungan antara karakteristik dan tingkat partisipasi peternak dalam penerapan IB digunakan uji stastik korelasi Rank Spearman (Walpole, 1992). Kemudian, untuk melihat perbedaan tingkat partisipasi peternak yang berdomisili di daerah lahan kering dan peternak yang berdomisili di daerah lahan persawahan, dilakukan uji UMann-Whitney (Siegel, 1988).

\section{Hasil dan Pembahasan}

\section{Karakteristik peternak}

Umur. Seluruh peternak yang dijadikan responden masih tergolong berumur produktif dengan interval 2060 tahun. Sebagian besar responden ( $48 \%$ ) telah berumur di atas 45 tahun, 24 persen berada pada kelompok umur $37 \quad 45$ tahun dan sisanya ( $28 \%$ ) berumur dibawah 37 tahun. 
Pendidikan. Tingkat pendidikan responden tergolong sangat rendah. Kendatipun seluruhnya pernah bersekolah, namun sebagian besar $(50 \%)$ tidak tamat SD. Adapun yang tamat SD dan SLTP, masing-masing $45 \%$ dan $5 \%$.

Jumlah tanggungan keluarga. Jumlah tanggungan keluarga responden bervariasi antara dua sampai tujuh orang, dengan persentase tertinggi adalah responden yang memiliki tanggungan antara empat sampai lima orang (44 $\%)$. Sisanya $(56 \%)$, terdiri dari kelompok responden yang memiliki tanggungan kurang dari empat orang $(20 \%)$ dan lebih dari 5 orang (36\%).

Penguasaan ternak sapi. Jumlah ternak sapi yang dikuasai oleh para responden bervariasi antara satu sampai lima ekor, dengan rata-rata 3 ekor. Sebagian besar responden (55 $\%$ menguasai ternak antara satu sampai dua ekor, $21 \%$ menguasai tiga ekor dan $24 \%$ menguasai lebih dari tiga ekor.

Pengalaman sebagai akseptor IB. Keikutsertaan peternak sebagai akseptor IB tergantung dari beberapa faktor. Salah satu di antaranya adalah adanya sapi betina dewasa yang sedang dipelihara. Secara agregat, pengalaman responden sebagai akseptor IB rata-rata dua tahun dan sebagian besar responden $(68 \%)$ memiliki pengalaman kurang dari tiga tahun. Selebihnya $(32 \%)$ terdiri dari kelompok responden yang memiliki pengalaman antara tiga sampai empat tahun dan lebih dari empat tahun, yaitu masing-masing $12 \%$ dan $20 \%$.

Pengetahuan tentang IB. Tingkat pengetahuan responden tentang hal-hal yang berhubungan dengan IB cukup bervariasi. Kelompok responden terbanyak adalah responden dengan tingkat pengetahuan yang termasuk dalam kategori rendah $(56 \%)$, kemudian diikuti oleh kelompok responden yang termasuk dalam kategori tinggi $(24 \%)$ dan sedang $(20 \%)$.

Responden dikategorikan memiliki tingkat pengetahuan yang tinggi, sedang, dan rendah apabila mengetahui hal-hal yang berhubungan dengan $\mathrm{IB}$, berturut-turut lebih dari $60 \%$, sama dengan $60 \%$ dan kurang dari $60 \%$.

\section{Partisipasi peternak}

Tabel I memperlihatkan bahwa secara keseluruhan tingkat partisipasi peternak tergolong sedang. Suatu fenomena yang menggembirakan adalah tingginya tingkat partisipasi peternak dalam penerapan IB pada sapi-sapi yang mereka usahakan, dan mereka sangat loyal terhadap ketentuan/peraturan yang telah ditetapkan. Hal ini menunjukkan, bahwa IB (sebagai suatu inovasi di bidang peternakan) sudah dapat diadopsi oleh para peternak, kendatipun hal tersebut belum tentu merupakan keputusan peternak yang bersifat permanen. Menurut Rogers dan Shoemaker (1971), seseorang yang telah memutuskan untuk menerima suatu inovasi, ada kemungkinan untuk meneruskan atau menghentikan penggunaannya (diskontinuasi). Diskontinuasi terjadi karena seseorang telah menemukan ide lain yang lebih baru, atau mungkin juga kecewa terhadap hasil yang diperoleh dari penerapan inovasi tersebut. Kemungkinan lainnya, pada tahap pengambilan keputusan seseorang menolaksuatu inovasi, tetapi beberapa waktu kemudian mengadopsi inovasi tersebut karena pandangannya telah berubah.

Berdasar pendapat di atas, dapat disimpulkan bahwa penerimaan masyarakat (khususnya masyarakat tani) terhadap suatu ide baru cenderung bersifat tidak permanen dan dipengaruhi oleh banyak faktor. Demikian pula halnya dengan keputusan para peternak untuk mengadopsi teknologi IB. Bagi mereka yang sudah mengadopsi, pada waktu-waktu mendatang bisa saja menghentikan penggunaan IB dengan berbagai alasan. Misalnya pelayanan dari inseminator yang kurang memuaskan, hasilnya yang tidak sesuai dengan harapan, dan lain sebagainya.

Data pada Tabel 1 juga menunjukkan bahwa para peternak cenderung bersifat pasif dalam upaya pengembangan program $\mathrm{IB}$. Hal ini tercermin dari rendahnya tingkat kehadiran mereka dalam pertemuan-pertemuan yang membahas IB, kurang aktif dalam memasyakatkan IB, dan kurang aktif dalam memberikan usul/pendapat tentang IB.

\section{Partisipasi peternak menurut daerah asal}

Tabel 2 dapat diketahui bahwa secara umum tingkat partisipasi peternak yang berdomisili di daerah dominan lahan persawahan 
Tabel 1. Tingkat partisipasi peternak terhadap pelaksanaan program IB (Level of farmers participation to execution of artificial insemination program)

\begin{tabular}{|c|c|c|}
\hline \multirow[b]{2}{*}{ Aspek partisipasi yang diamati (Participation aspect observed) } & \multicolumn{2}{|l|}{ Total } \\
\hline & $\begin{array}{l}\text { Frekuensi (orang) } \\
\text { (Frequency (person)) }\end{array}$ & $(\%)$ \\
\hline \multicolumn{3}{|l|}{$\begin{array}{l}\text { Penerapan IB pada sapi sendiri (Application of AI on their own } \\
\text { belongings) }\end{array}$} \\
\hline a. Tinggi $(>65 \%$ IB) $($ High $(>65 \%$ AI) $)$ & 73 & 73 \\
\hline b. Sedang ( $45-65 \%$ IB) (Medium $(45-65 \%$ AI)) & 25 & 25 \\
\hline c. Rendah $(<45 \%$ IB $)(\operatorname{Low}(<45 \%$ AI $))$ & 2 & 2 \\
\hline \multicolumn{3}{|l|}{$\begin{array}{l}\text { Kehadiran dalam pertemuan yang membahas IB (Presence in } \\
\text { attending the meeting about AI) }\end{array}$} \\
\hline a. Tinggi (kehadiran $>65 \%$ ) (High (presence $>65 \%)$ ) & 6 & 6 \\
\hline b. Sedang (kehadiran $45-65 \%$ ) (Medium (presence $45-$ & 13 & 13 \\
\hline c. Rendah (kehadiran < $45 \%)($ Low $($ presence $<45 \%)$ ) & 81 & 81 \\
\hline \multicolumn{3}{|l|}{$\begin{array}{l}\text { Loyalitas terhadap ketentuan/peraturan (Loyality to the } \\
\text { memorandum of understanding) }\end{array}$} \\
\hline a. Tinggi (sangat loyal) (High (very loyal)) & 93 & 93 \\
\hline b. Sedang (cukup loyal) (Medium (fairly loyal)) & 7 & 7 \\
\hline c. Rendah (kurang loyal) (Low (less loyal)) & 0 & 0 \\
\hline \multicolumn{3}{|l|}{ Aktivitas memasyarakatkan IB (Activity on socializing AI) } \\
\hline a. Tinggi (sangat aktif) (High (very active)) & 25 & 25 \\
\hline b. Sedang (cukup aktif) (Medium (fairly active)) & 39 & 39 \\
\hline c. Rendah (kurang aktif) (Low (less active)) & 36 & 36 \\
\hline \multicolumn{3}{|l|}{ Memberi usul/ pendapat (Giving suggestion/opinion) } \\
\hline a. Tinggi (sangat aktif) (High (very active)) & 1 & 1 \\
\hline b. Sedang (cukup aktif) (Medium (fairly active)) & 21 & 21 \\
\hline c. Rendah (kurang aktif) (Low (less active)) & 78 & 78 \\
\hline
\end{tabular}

lebih tinggi daripada di daerah dominan lahan kering. Hal tersebut tercermin dari perbandingan jumlah skor partisipasi yang dicapai, skor ratarata per aspek (jenis) partisipasi dan per peternak disajikan pada Tabel 3.

Adapun aspek partisipasi yang berbeda sangat nyata adalah aktivitas dalam memasyarakatkan IB $(Z=3097 ; \quad P<0,01)$, sedangkan yang berbeda nyata adalah partisipasi dalam memberikan usul/pendapat tentang IB $(\mathrm{Z}=2767 ; \mathrm{P}<0,05)$. Terjadinya perbedaan tersebut diduga erat kaitannya dengan perbedaan karakteristik individu petani peternak pada kedua bagian daerah tersebut. Seperti telah dikemukakan terdahulu, dari delapan karakteristik individu yang diamati hanya tiga faktor yang berhubungan secara nyata dengan sebagian aspek partisipasi yang diamati. Ketiga faktor dimaksud adalah umur, tingkat pendidikan, dan tingkat pengetahuan. Namun dari ketiga faktor tersebut, diduga faktor pengetahuan yang paling memegang peranan penting. Pada Tabel 9 terlihat bahwa tingkat petani peternak yang berdomisili di daerah dominan lahan persawahan adalah lebih tinggi daripada petani peternak yang berdomisili di daerah lahan kering.

\footnotetext{
Hubungan karakteristik dengan tingkat partisipasi peternak.

Hubungan karakteristik peternak dengan aspek-aspek partisipasi yang diamati terlihat pada Tabel 4.
} 
Tabel 2. Tingkat partisipasi peternak terhadap pelaksanaan program IB menurut daerah asal (Level of breeder participation to execution of AI program based on the area of origin).

\begin{tabular}{|c|c|c|c|c|}
\hline \multirow{2}{*}{$\begin{array}{l}\text { Aspek partisipasi yang diamati } \\
\text { (Participation aspect observed) }\end{array}$} & \multicolumn{2}{|c|}{$\begin{array}{l}\text { Daerah dominan lahan } \\
\text { persawahan (Rice field } \\
\text { dominant area) }\end{array}$} & \multicolumn{2}{|c|}{$\begin{array}{l}\text { Daerah dominan lahan kering } \\
\text { (Dry land dominant area) }\end{array}$} \\
\hline & $\begin{array}{c}\text { Frekuensi (Orang) } \\
\text { (Frequency (person)) }\end{array}$ & $(\%)$ & $\begin{array}{l}\text { Frekuensi (Orang) } \\
\text { (Frequency (person)) }\end{array}$ & $(\%)$ \\
\hline \\
\hline $\begin{array}{l}\text { (Application of AI on their own } \\
\text { belongings) } \\
\text { a. Tinggi }(>65 \% \text { IB) (High }>65 \%\end{array}$ & & & & \\
\hline $\begin{array}{l}\text { a. Tinggi }(>65 \% \text { IB) (High }(>65 \%) \\
A I I)\end{array}$ & 35 & 70 & 38 & 76 \\
\hline $\begin{array}{l}\text { b. Sedang ( } 45-65 \% \text { IB) (Medium (45- } \\
\quad 65 \% \text { Al)) }\end{array}$ & 13 & 26 & 12 & 24 \\
\hline c. Rendah $(<45 \%$ IB $)($ Low $(<45 \% A I))$ & 2 & 4 & 0 & 0 \\
\hline $\begin{array}{l}\text { Kehadiran dalam pertemuan yang } \\
\text { membahas IB }\end{array}$ & & & & \\
\hline $\begin{array}{l}\text { (Presence in attending the meeting } \\
\text { about } A I \text { ) }\end{array}$ & & & & \\
\hline $\begin{array}{l}\text { a. Tinggi (kehadiran }>65 \%) \\
(\text { High (presence }>65 \%) \text { ) }\end{array}$ & 5 & 10 & 1 & 2 \\
\hline b. Sedang (kehadiran $45-65 \%$ ) & & & & \\
\hline (Medium(presence $45-65 \%)$ ) & 4 & 8 & 9 & 18 \\
\hline $\begin{array}{l}\text { c. Rendah (kehadiran }<45 \%) \\
\text { (Low (presence }<45 \%) \text { ) }\end{array}$ & 41 & 82 & 40 & 80 \\
\hline $\begin{array}{l}\text { Loyalitas terhadap ketentuan/peraturan } \\
\text { (Loyality to the memorandum of } \\
\text { understanding) }\end{array}$ & & & & \\
\hline a. Tinggi (sangat loyal) (High (very & 44 & 88 & 49 & 98 \\
\hline b. Sedang (cukup loyal) (Medium & 6 & 12 & 1 & 2 \\
\hline $\begin{array}{l}\text { c. Rendah (kurang loyal) (Low (less } \\
\text { loyal)) }\end{array}$ & 0 & 0 & 0 & 0 \\
\hline $\begin{array}{l}\text { Aktivitas memasyarakatkan IB } \\
\text { (Activity on socializing AI) }\end{array}$ & & & & \\
\hline $\begin{array}{l}\text { a. Tinggi (sangat aktif) (High (very } \\
\text { active)) }\end{array}$ & 21 & 42 & 4 & 8 \\
\hline $\begin{array}{l}\text { b. Sedang (cukup aktif) (Medium (fairly } \\
\text { active)) }\end{array}$ & 19 & 38 & 20 & 40 \\
\hline $\begin{array}{l}\text { c. Rendah (kurang aktif) (Low less } \\
\text { active)) }\end{array}$ & 10 & 20 & 26 & 52 \\
\hline $\begin{array}{l}\text { Memberi usul/ pendapat } \\
\text { (Giving suggestion/opinion) }\end{array}$ & & & & \\
\hline $\begin{array}{l}\text { a. Tinggi (sangat aktif) (High (very } \\
\text { active)) }\end{array}$ & 0 & 0 & 1 & 2 \\
\hline $\begin{array}{l}\text { b. Sedang (cukup aktif) (Medium (fairly } \\
\text { active)) }\end{array}$ & 16 & 32 & 5 & 10 \\
\hline $\begin{array}{l}\text { c. Rendah (kurang aktif) (Low (less } \\
\text { active)) }\end{array}$ & 34 & 68 & 44 & 88 \\
\hline
\end{tabular}


Umur dengan tingkat partisipasi. Umur Peternak, kecuali dengan aspek loyalitas terhadap ketentuan/peraturan yang telah disepakati, ternyata berkorelasi negatif dengan aspek-aspek partisipasi lainnya. Namun demikian, hanya dengan aspek penerapan IB pada sapi sendiri dan aspek pemberian usul/pendapat tentang IB yang memperlihatkan korelasi yang bermakna $(P<0,05)$ dengan koefisien korelasi masing-masing sebesar 0,20767 dan 0,20758 . Hal ini berarti bahwa semakin tua umur peternak, maka tingkat partisipasinya dalam penerapan IB dan memberikan usul/pendapat tentang IB cenderung semakin rendah atau menurun. Fakta ini sesuai dengan pendapat Dahama dan Bhatnagar (1980) yang menyatakan bahwa kemampuan atau kapasitas belajar seseorang meningkat pada batas waktu tertentu dan kemudian menurun sesuai dengan bertambahnya usia.

Pendidikan dengan tingkat partisipasi. Umur peternak ternyata menunjukkan korelasi yang positif dan bermakna $(\mathrm{P}<0,05)$ dengan semua aspek partisipasi yang diamati. Berdasarkan hal tersebut dapat dinayatakan, bahwa peternak yang berpendidikan lebih tinggi cenderung menunjukkan partisipasi yang lebih tinggi dibandingkan dengan peternak yang berpendidikan lebih rendah. Hasil penelitian ini menunjukkan kesamaan dengan penelitian Khaeruddin (1992), yang mengadakan penelitian tentang hubungan antara tingkat pendidikan dengan partisipasi masyarakat dalam pembangunan pertanian.

Tabel 3. Perbandingan tingkat partisipasi peternak menurut daerah asal (Comparison of farmer participation level on various area of origin)

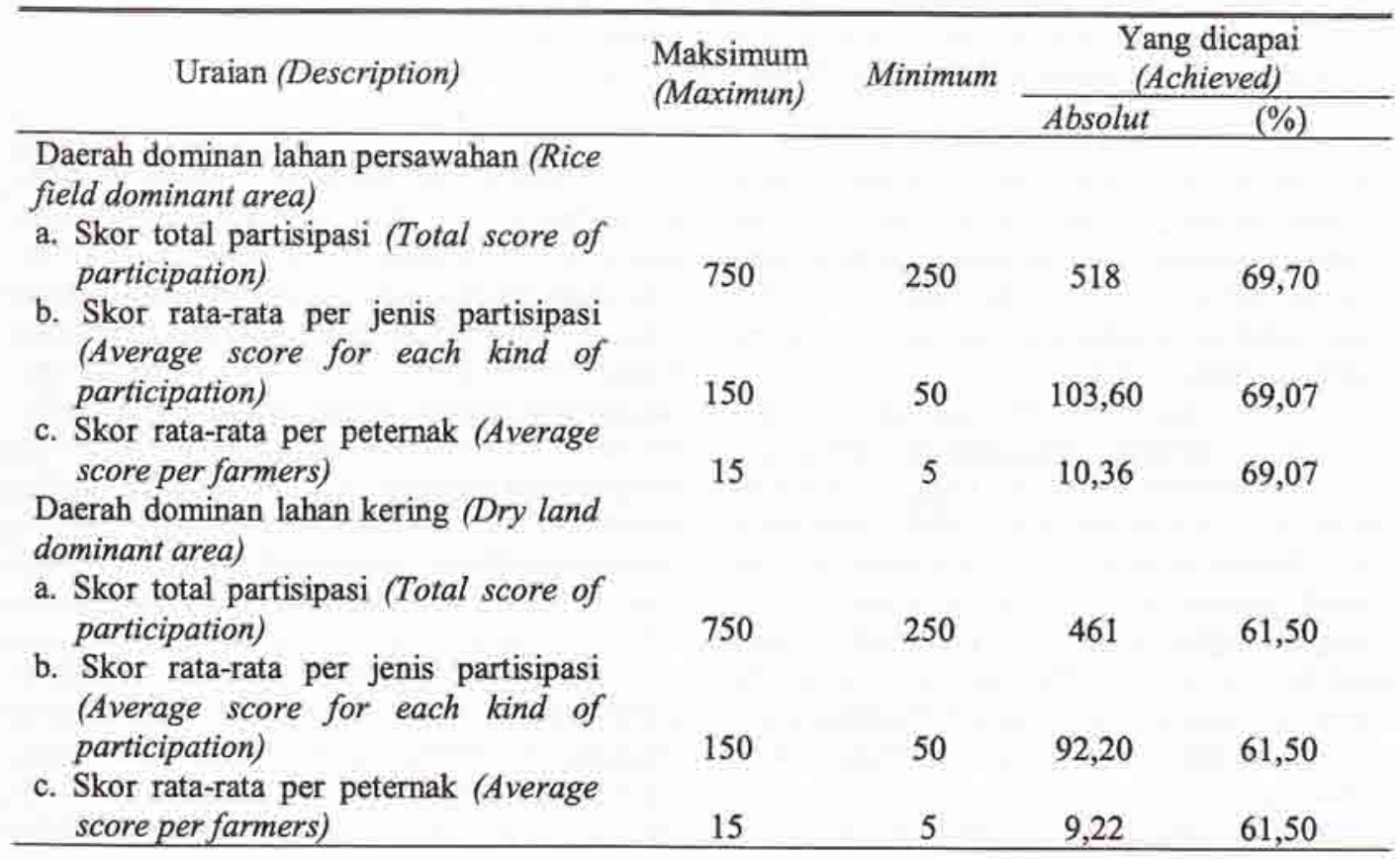


Tabel 4. Hubungan karakteristik dengan tingkat partisipasi peternak (Relationship between characteristic and level of farmer participation)

\begin{tabular}{|c|c|c|c|c|c|}
\hline \multirow{2}{*}{$\begin{array}{c}\text { Karakteristik individu } \\
\text { (Individual characteristic) }\end{array}$} & \multicolumn{5}{|c|}{ Aspek partisipasi (Nilai: rs) (Participation aspects (Point: rs)) } \\
\hline & $\mathrm{Y} 1$ & $\mathrm{Y} 2$ & $\mathrm{Y} 3$ & $\mathrm{Y4}$ & Y5 \\
\hline Umur (Age) & $-0,20767^{*}$ & $-0,07266$ & $-0,07266$ & $-0,07266$ & $-0,20758^{*}$ \\
\hline $\begin{array}{l}\text { Tingkat pendidikan (Level of } \\
\text { education) }\end{array}$ & $0,21177^{*}$ & $0,23667^{*}$ & $0,21626^{*}$ & $0,27124^{*}$ & $0,24197^{*}$ \\
\hline $\begin{array}{l}\text { Jumlah tanggungan keluarga } \\
\text { (Number of familly }\end{array}$ & & & & & \\
\hline responsibility) & 0,00429 & $-0,12818$ & 0,04684 & 0,10685 & 0,09192 \\
\hline $\begin{array}{l}\text { Penguasaan ternak sapi } \\
\text { (Number of belonging) }\end{array}$ & 0,01827 & $-0,02231$ & $-0,03003$ & 0,00088 & $-0,00696$ \\
\hline $\begin{array}{l}\text { Pengalaman sebagai Peserta IB } \\
\text { (Experience on conducting } \mathrm{AI} \text { ) } \\
\text { Tingkat pengetahuan tentang IB }\end{array}$ & 0,07491 & $-0,10459$ & 0,02642 & 0,04797 & 0,07688 \\
\hline (Level of knowledge about AI) & 0,06600 & 0,00473 & $0,26339^{*}$ & $0,22819^{*}$ & $0,20221^{*}$ \\
\hline $\begin{aligned} \mathrm{Y} 1= & \text { Penerapan IB pada sapi send } \\
\mathrm{Y} 2= & \text { Kehadiran dalam rapat yang } \\
\mathrm{Y} 3= & \text { Loyalitas terhadap ketentua } \\
& \text { of understanding) } \\
\mathrm{Y} 4= & \text { Aktivitas dalam memasyara } \\
\mathrm{Y} 5= & \text { Memberikan usul/pendapat } \\
& * \text { Signifikan }(\mathrm{P}<0,05) \text { (Sign }\end{aligned}$ & $\begin{array}{l}\text { iri (Applicat } \\
\text { membahas I } \\
\text { a/peraturan } \\
\text { atkan IB (A. } \\
\text { entang IB (C } \\
\text { icant }(P<0 \text {. }\end{array}$ & $\begin{array}{l}\text { of } A I \text { on } t \\
\text { (Presence } \\
\text { ng telah di }\end{array}$ & $\begin{array}{l}\text { ir own belo } \\
\text { attending th } \\
\text { pakati (Loy } \\
\text { izing AI) } \\
\text { m/opinion) }\end{array}$ & $\begin{array}{l}\text { gings) } \\
\text { meeting a } \\
\text { ity to the }\end{array}$ & $\begin{array}{l}\text { ut AI) } \\
\text { morandum }\end{array}$ \\
\hline
\end{tabular}

Dilaporkan bahwa antara kedua variabel tersebut terdapat hubungan yang positif dan bersifat nyata. Demikian pula dengan hasil penelitian Madrie (1986); Nizar (1990); Hadi (1991) dan Baso (1985), masing-masing dengan obyek penelitian yang berbeda.

Beberapa ahli mengaitkan tingkat pendidikan dengan pengetahuan. Seseorang yang berpendidikan lebih tinggi cenderung memiliki pengetahuan yang lebih luas/tinggi dibandingkan dengan orang yang berpendidikan relatif rendah. Dalam hal ini, Long (1973) menghubungkan tingkat pengetahuan dengan partisipasi seseorang. Dikatakan, seseorangyang memiliki pengetahuan dan kesadaran yang tinggi cenderung berpartisipasi semakin tinggi dalam pembangunan.

Jadi, tingkat pendidikan, pengetahuan, dan kesadaran merupakan faktor-faktor yang dapat mendorong seseorang untuk berpartisipasi secara sehat, dalam arti berpartisipasi atas kemauannya sendiri.
Tanggungan keluarga dengan tingkat partisipasi. Variabel jumlah tanggungan keluarga menunjukkan hubungan yang kurang bermakna dengan semua aspek partisipasi yang diamati $(P>0,05)$. Hasil penelitian ini sama dengan hasil penelitian Nizar (1990), yang melaporkan bahwa antara jumlah tanggungan keluarga dengan aspek-aspek partisipasi yang diamati tidak terdapat hubungan yang nyata. Ini berarti, jumlah tanggungan keluarga bukan merupakan faktor yang mempengaruhi tingkat partisipasi peternak dalam pelaksanaan program IB.

Penguasaan ternak sapi dengan tingkat partisipasi. Seperti halnya variabel jumlah tanggungan keluarga, penguasaan ternak sapi juga menunjukkan hubungan yang kurang bermakna ( $>>0,05)$ dengan semua aspek partisipasi yang diamati. Hal ini dapat dipahami karena umumnya para peternak tidak hanya memelihara sapi betina dewasa, tetapi di antaranya ada yang masih muda, jantan, bahkan 
dalam kurun waktu tertentu tidak memelihara ternak sama sekali.

\section{Pengalaman dengan tingkat} partisipasi. Pengalaman peternak sebagai peserta IB juga bukan merupakan faktor utama yang memotivasi peternak untuk berpartisipasi dalam pelaksanaan program IB. Hasil analisis data menunjukkan bahwa antara variabel pengalaman dan semua aspek partisipasi yang diamati cenderung kurang bermakna $(P>0,05)$. Dengan demikian, dapat dikatakan bahwa peternak yang memiliki pengalaman yang lebih tinggi/lama, tidak secara otomatis akan memperlihatkan partisipasi yang lebih tinggi dibandingkan dengan peternak yang lebih rendah/sedikitpengalamannya.

Pengetahuan dengan tingkat partisipasi. Antara tingkat pengetahuan peternak tentang IB dan aspek-aspek partisipasi yang diamati ternyata menunjukkan penomena yang menarik. Kendatipun memperlihatkan korelasi yang kurang bermakna dengan aspek penerapan IB dan tingkat kehadiran dalam rapat yang membahas IB, namun dengan aspek loyalitas terhadap ketentuan/peraturan yang telah disepakati, aktivitas memasyarakatkan IB dan memberikan usul/pendapat tentang IB, justru menunjukkan korelasi yang positif dan bermakna $(P<0,05)$.

Sebagaimana diketahui, bahwa sebagian besar responden memiliki tingkat pengetahuan yang rendah tentang IB, namun data pada Tabel 1 memperlihatkan tingginya tingkat penerapan IB pada sapi yang diusahakan. Tingginya tingkat partisipasi peternak dalam hal ini, diduga merupakan hasil belajar (belajar sikap) dari peternak lain yang telah berhasil, dan hal ini diakui oleh $57 \%$ peternak yang diwawancarai. Menurut Winkel (1989), yang dimaksud dengan belajar sikap adalah kecenderungan untuk menerima atau memperoleh sesuatu obyek berdasarkan penilaian terhadap obyek itu sebagai hal yang berguna/berharga (sikap positif) atau tidak berguna/berharga (sikap negatif). Hampir sama dengan pendapat Mosher (1983), bahwa orang dapat belajar dari pengalaman tanpa menerima pengajaran secara formal. Pengalaman dalam hal ini, bukan saja pengalaman diri sendiri (hasil belajar), tetapi juga pengalaman orang lain yang telah lebih dulu menerapkan teknologi IB tersebut. Demikian pula halnya dengan kurang bermaknanya hubungan antara tingkat pengetahuan dan tingkat kehadiran dalam rapat/pertemuan yang membahas IB. Rendahnya tingkat partisipasi peternak bukan semata-mata diakibatkan oleh rendahnya tingkat pengetahuan mereka tentang IB.

Berbeda dengan kedua hal di atas, antara tingkat pengetahuan dengan tiga aspek partisipasi lainnya, yakni loyalitas terhadap ketentuan/peraturan yang telah disepakati; aktivitas dalam memasyarakatkan IB; memberikan usul/pendapat tentang IB, ternyata menunjukkan hubungan yang positif dan bermakna dengan koefisien rs, masing-masing sebesar 0,26339; 0,22819; dan 0,20221. Kendatipun tingkat pengetahuan tentang IB sebagian peternak tergolong rendah, namun tingkat kesadaran dan rasa kebersamaan di antara mereka masih cukup kuat. Rendahnya tingkat pengetahuan sebagian besar peternak cenderung berhubungan dengan rendahnya tingkat pendidikan mereka. Pendidikan dan pengetahuan yang terbatas dapat menjadi kendala dalam menyerap informasi, karena dengan terbatasnya pengetahuan menyebabkan kesempatan orang untuk menyerap informasi yang ada menjadi terbatas pula (Khaeruddin, 1992). Hampir senada dengan pendapat Muller (1980), yang menyatakan bahwa tarap pendidikan yang sangat rendah pada umumnya bergandengan dengan informasi dan pengertian yang serba terbatas. Dengan demikian, segala kesempatan juga menjadi serba terbatas.

\section{Kesimpulan}

1. Karakteristik individu peternak yang dominan adalah : (a) seluruh peternak masih berusia produktif, (b) sebagian besar tidak tamat SD, (c) jumlah tanggungan keluarga sebagian besar antara empat sampai lima orang, (d) jumlah pemilikan ternak sapi ratarata tiga ekor, (e) pengalaman sebagai akseptor IB rata-rata dua tahun, dan (f) tingkat pengetahuan tentang IB sebagian besar tergolong rendah.

2. Tingkat partisipasi peternak secara rata-rata tergolong sedang, dengan catatan partisipasi 
peternak yang berdomisili di daerah dominan lahan persawahan lebih tinggi daripada partisipasi peternak yang berdomisili di daerah dominan lahan kering.

3. Umur mempunyai hubungan yang negatif dengan partisipasi peternak dalam penerapan IB dan memberikan usul/pendapat tentang IB; pendidikan mempunyai hubungan yang positif dengan semua aspek partisipasi yang diamati; sedangkan tingkat pengetahuan mempunyai hubungan yang positif dengan partisipasi peternak dalam memasyarakatkan IB dan memberikan usul/pendapat tentang IB.

\section{Daftar Pustaka}

Ancok, D. 1991. Validitas dan Reliabilitas Instrumen Penelitian. Dalam Metode Penelitian Survai. Diedit oleh M. Singarimbun dan S. Effendi. LP3ES, Jakarta.

Baso, A. 1985. Dampak Kuliah Kerja Nyata (KKN) pada Masyarakat Desa. Disertasi. Fakultas Pascasarjana IPB, Bogor.

Dahama, O. P. dan O. P Bhatnagar, 1980. Education and Communication for Development. Oxford \& IBH Publishing Co., New Delhi.

Hadi, S. 1991. Partisipasi Tokoh Masyarakat Desa pada Kegiatan Kuliah Kerja Nyata (KKN) Universitas Jambi. Tesis. Program Pascasarjana IPB, Bogor.

Hunneryager, S. G. dan I. L. Heckam. 1992. Partisipasi dan Dinamika Kelompok. Dahara Prize, Semarang.

Iskandar, J. dan C. Nitimihardjo. 1992. Beberapa Indeks dan Skala Pengukuran VariabelVariabel Sosial dan Psikologi. Kopma Bersama An Naba DKMAlAhsan, STKS, Bandung.

Khairuddin H. 1992. Pembangunan Masyarakat: Tinjauan Aspek Sosial, Ekonomi dan Perencanaan. Liberty, Yogyakarta.
Long, H. B. 1973. Approach to Community Development. National University Extension Association and The American College.

Madrie, 1986. Beberapa Faktor Penentu Partisipasi Anggota Masyarakat dalam Pembangunan Pedesaan. Disertasi. Fakultas Pascasarjana IPB, Bogor.

Mosher, A. T. 1983. Menggerakkan dan Membangun Pertanian : Syarat-syarat Pokok Pembangunan dan Modernisasi. CV. Yasaguna, Jakarta.

Muller, J. 1980. Pendidikan Sebagai Jalan Pembebasan dari Cengkeraman Kemelaratan. Disertasi. Fakultas Pascasarjana IKIP, Jogyakarta.

Ndraha, T. 1990. Pembangunan Masyarakat. Rineka Cipta, Bandung.

Nizar T, M. 1990. Partisipasi Kontaktani dalam Penyusunan Program Pertanian Padi Sawah : Studi Kasus di WKBPP Cibarusah Kabupaten Bekasi Propinsi Jawa Barat. Tesis, Program Pascasarjana IPB, Bogor.

Rogers, E. M. dan F. F. Shoemaker. 1971. Communication of Innovation. The Free Press, New York.

Siegel, S. 1988. Statistika Nonparametrik untuk Ilmu-Ilmu Sosial. PT. Gramedia Pustaka Utama, Jakarta.

Soetarso. 1979. Praktek Pekerjaan Sosial dalam Pembangunan Masyarakat. STKS, Bandung.

Walpole, R. E. 1992. Pengantar Statistika : Edisi ke-3. PT. Gramedia Pustaka Utama, Jakarta.

Wignjosoebroto, S. 1989. Pengolahan dan Analisa Data. Dalam Metode-Metode Penelitian Masyarakat, Diedit oleh Koentjaraningrat. PT. Gramedia, Jakarta.

Winkel, W. S. 1989. Psikologi Pengajaran. PT. Gramedia, Jakarta. 